\title{
CAN MINOR FRUIT CULTIVATION CHANGE THE LIVELIHOOD OF THE MARGINAL PEASANTS? A CASE STUDY FROM BANGLADESH
}

\author{
Kabir M.S.22,Salehin M.M.23, Elena Jovicic ${ }^{24}$
}

\begin{abstract}
Lemon (lebu) cultivation, a minor fruit production activity, is increasingly becoming popular among the marginal peasants. The present study aimed at exploring the potentials of lemon production and its impact on the changes in the livelihood pattern of the rural farmers as well as its impact on women empowerment. Based on qualitative and quantitative data collected from Mymensingh district in Bangladesh in 2015, this paper argues that life and livelihood of the citrus producer has significantly changed over the last decade. Income from the sale of lemon is the principal livelihood means and gender non-differentiated participation in the production process further enhanced the sustainability of the livelihoods. It also contributed to employment generation for those who are not directly involved in the lemon cultivation such as power tiller driver, irrigation pump driver, fertilizer \& pesticide retailer, small lemon collector, lemon supplier in the study area. Moreover, increased participation of women in the citrus cultivation has changed not only their economic well-being but also social status, honor, planning and decision making power, and self-esteem. This study also shows that marginal and vulnerable poor women including landless women, female member of women headed household and widows significantly benefited from citrus cultivation. Yet, lack of cooperative society, financial support, credit facility, technical support, storage facility and marketing support are identified as the potential problems to achieve a sustainable growth of lemon production activity.
\end{abstract}

KEYWORDS: citrus production, livelihood, marginal peasants, women empowerment JEL: J16, O13, 015

UDC: 338.439.4:634.33(549.3)

\footnotetext{
${ }^{22}$ Department of Rural Sociology Bangladesh Agricultural University, Bangladesh,e-mail: mskabir786@gmail.com

${ }^{23}$ Department of Rural Sociology Bangladesh Agricultural University,

Bangladesh

${ }^{24}$ Institute of Economic Sciencies,Belgrade, Serbia, elena.baranenko@ien.bg.ac.rs
} 


\section{Introduction}

Lemon (lebu), a citrus fruit (Citrus limon) of Indian origin is gaining popularity among the farmers due to good economic prospect. Although their production is concentrated in Sylhet, Chittagong and the Chittagong Hill Tracts region of Bangladesh, it is getting popular in many other parts of the country. According to Bangladesh Bureau of Statistics, about 16000 metric tonnes of citrus fruits were produced in the country in 2008-09 and its production increased to 21000 metric tonnes during 2009-10 (BBS, 2015). Although it is not a major fruit and not widely produced, due to climatic and soil condition as well as expanding market and export potential, there is a sharp rise in the commercial lemon production.

Citrus is an important source of Vitamin C. In Bangladesh about 93 percent of people are vitamin $\mathrm{C}$ deficient since the mean intake of Vitamin $\mathrm{C}$ is far below from the recommended dietary allowance (Ahmed et al., 1998; Nielsen, 2000; Hels et al., 2003; Khan,Ahmed, 2005). Therefore, increased production of citrus could potentially provide the people with necessary vitamin C. Moreover, homestead and community cultivation as well as commercial production could be an important contributor in the total citrus production. Consequently, it could be a potential source of livelihood for many rural poor people. For example, previous studies on small-scale agriculture show positive impact on the improvement of the livelihood of the rural poor farmers. For example, Kabir et al., (2012) shows how small entrepreneurs in agriculture sector can achieve sustainable livelihood through access to a range of livelihood assets. They found a positive and significant correlation between small agriculture enterprise and improvement of livelihood. Salehin et al., (2009) showed a significant increase in annual income, food consumption expenditure, housing environment and family status of the framers due to the adoption of new agricultural technologies. Despite of growing interest in lemon farming, there is no significant study on the subject. Therefore, the present paper aims at exploring the role of lemon production on livelihood status of rural marginal peasant in Bangladesh. The main objectives of the paper are:

- $\quad$ to explore the potentials, problems and probable solutions of lemon production in Bangladesh

- to assess the impact of citrus production on changes in the livelihoods of the marginal peasant

- to investigate the women's participation in citrus production and its impact on women's empowerment.

\section{Methodology}

For the purpose of this study, both qualitative and quantitative methods of data were used. For the present research Kathalia, a village situated in Daogaon union Parishad in Muktagacha Upazila of Mymensingh district was purposively selected. Yet, in the selection process, the researcher consulted with IFDC project staff who is implementing IFDC project in cooperation with the department of agriculture extension (DAE). The selection of the study area was based on the following main consideration:

- The area is enriched in lemon production

- Availability of lemon producers in clusters

- Easy accessibility to the village because of better communication facilities 
- Cooperation from the respondents was exponents, expected to be high and possibility of getting reliable data and finally

- $\quad$ No study of this type was done previously in the area

The researcher used both quantitative and qualitative information to produce the paper. Qualitative information were primarily collected by the researcher through Focus Group Discussion, transact walk and field observation and in-depth interviews during JanuaryMarch 2015. Researcher conducted in-depth interviews with 21 farmers (male-10 and female-11) with the use of semi-structured interview schedule. However quantitative data were gathered from Upazila officials, respective government department, and different study report.

\section{Result and discussion}

\section{Trends in lemon production in Bangladesh}

Lemon has been the part of homestead gardening in Bangladesh since long. However, it has come to the spot light in the early 2000 s and has increasingly become popular among the poor farmer. Thus, we see a drastic rise in the production citrus over the last decade. For example, during 2004 while the total citrus production was approximately 5000 metric tons, it became doubled in 2006. The following graphs show the growth in production of lemon over a decade in Bangladesh.

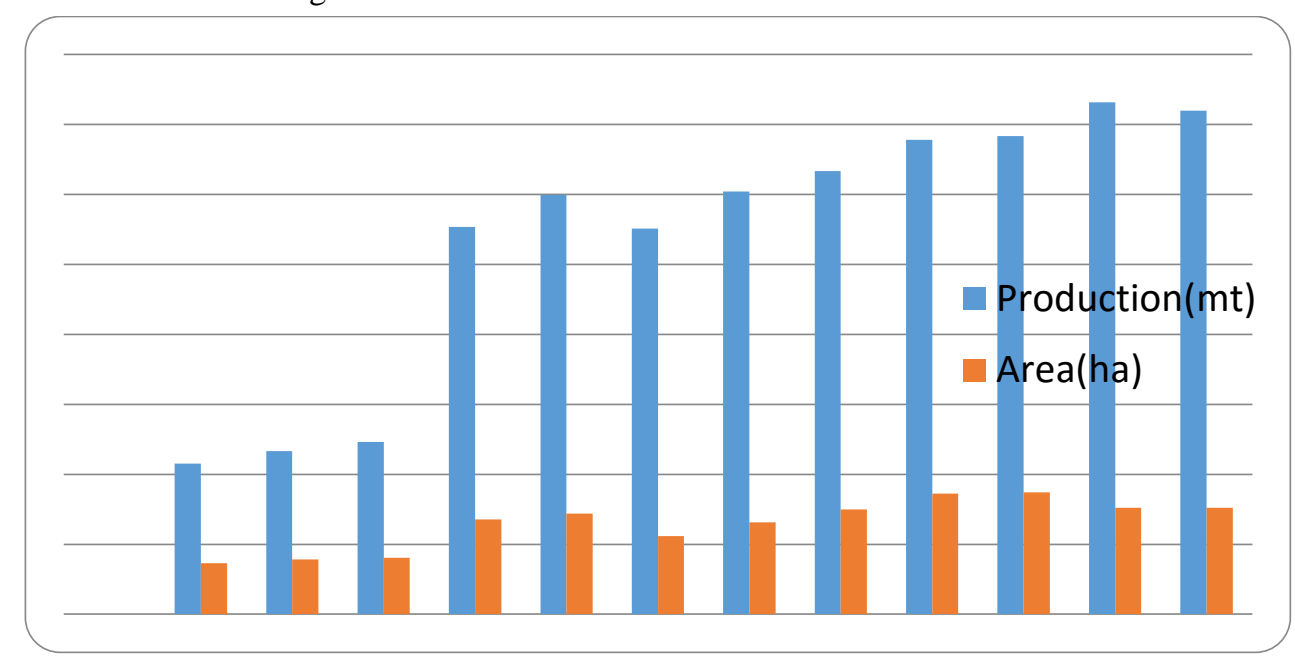

Figure 1: Trends in Lemon Production in Bangladesh Source: BBS (2015)

Moreover, compared to the main crop i.e. rice and other crops lemon production tend to be more profitable. The following graph compared the net profit of lemon production to other crops. 


\section{Lemon production in the study area}

In Kathalia, lemon cultivation has started about eight to ten years ago. In this area rural farmers used to cultivate banana and pineapple before lemon cultivation. However, they turned to lemon production in large volume due high market price. In lemon cultivation practice, farmers in Kathalia introduced different types of modern lemon varieties of lemon. They collected high yielding lemon varieties from Sylhet, Tangail, and Manikgonj. They collected cuttings of Elachi, Kagozi, and Colombo lemon variety from different locations of the Bangladesh.

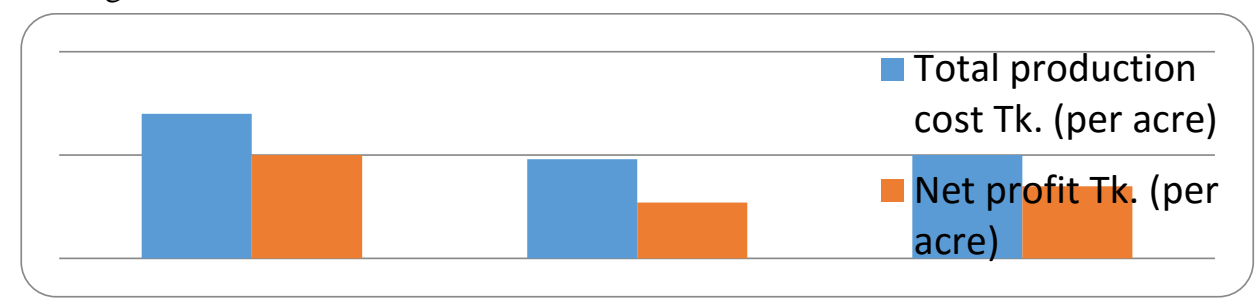

Figure 2: Comparison of lemon and other crops in terms of production cost and net profit

$$
\text { Source: BBS (2015) }
$$

\section{Descriptions of the Varieties}

There are three type lemons under cultivation in Kathalia. These are Ealchi lebu, Kagozi lebu and Colombo lebu. Kagozi lebu is produced for only one time in a year, in March- April. Elachi lebu and Colombo lebu are produced in all time. Colombo lebu has two kinds e.g. Manikgong Colombo lebu and Mymensingh Colombo lebu. Manikgong Colombo lebu has better production than Mymensingh Colombo lebu. Colombo lebu can tolerate water logging for seven to eight days.

Table 1: Different Varieties of Lemon

\begin{tabular}{||l|l|l|l|}
\hline \multicolumn{1}{|c|}{ Local name } & Common name & \multicolumn{1}{|c|}{ Scientific name } & \multicolumn{1}{c|}{ Varieties } \\
\hline Elachi lebu & Lemon & Citrus limon & $\begin{array}{l}\text { BARI lebu-1,2,3 BAU lebu-2, } \\
\text { BAU lebu-3 }\end{array}$ \\
\hline Kagozi lebu & Lime & C.aurantifolia & BAU kagozi lebu-1 \\
\hline Colombo lebu & & & $\begin{array}{l}\text { Colombo-Manikgong, Colombo- } \\
\text { Mymensingh }\end{array}$ \\
\hline
\end{tabular}

The farmers prefer the grafting seedling for their lemon garden because within one year of transplanting it gives fruit. In that area, the farmers prefer nine foot distance between plants. About 400-500 seedlings are transplanted per acre.

Farmers use fertilizer and organic matter in their lemon garden. Cost of gardening is almost about 5000 taka per acre. They use urea, triple superphosphate (TSP), muriate of potash (MOP) as fertilizer, and cow dung as organic matter. 
Crop diversification occurred in Kathalia due to lemon production. Before lemon cultivation two or three crops were produce there. After lemon cultivation, five or more inter crops (sathi foshol) like Papaya, Zinger, Turmeric, Onion, Garlic, Kolocasia. Different types of vegetables are produced in the lemon field as intercrop, which increase the cropping intensity of that locality as well as increase the income from different crops, and ultimately it improves the economic status of the community.

Besides the lemon cultivation, they produce rice, winter season high value vegetables like cabbage, cauliflower, tomato etc. They also raise livestock and poultry in their homestead area, which helps them to additional income for their family needs.

Lemon cultivation also changed the infrastructure of Kathalia. Local government division constructed a puccka road for creating linkages with the different growth center of that area like Rasulpur, Gabtoli, Madhupur and Muktagacha. People supply their product very easily to the different location of the country and they get fare price of their product.

\section{Why respondents are more interested for more lemon production?}

Field data revels that there are many factors behind the adoption of lemon cultivation instead of other crops. Some of these are identified as follows:

- Maximum and quick return compared to other production

- Market demand of the products

- Proper site utilization

- Low investment cost

- Higher employment opportunity

- Opportunity to increase standard of living

- Opportunity to maximize crop diversification

- $\quad$ Reduce pressure on natural forest

\section{Lemon production and sustainable livelihood}

One of the most significant impacts of lemon cultivation is the conversion of fallow high land into productive lemon orchard and consequently adding unemployed workforce into production wheel. The area now under the lemon production used to be fallow land. Although this cultivable land is suitable for cereal crops, they are also appropriate for horticultural crops like lemon and other fruits. Since these are mainly khas (government) land and consequently became fallow land. This ownership condition of the land made it difficult to get access to it for cultivation. Moreover, the people who are engaged in lemon production are landless, day labor and unemployed and hence are considered as marginal population. Therefore, government decision to lease out the land for 99 years now made it easy for the marginal farmers to start lemon cultivation.

Involvement of the marginal peasants in lemon production brought much fortune to the people. Before lemon cultivation, people of Kathalia suffered in a number of ways. They lived in a poor condition. Due to the involvement in lemon production, annual income of the households has increased in many folds. Their yearly income reached up to 50000-60000 
Taka from one acre lemon field, deducting all types of production cost. Many of the participants used to live in house made CI sheet and mud, but they now won house made of brick and CI Sheet. Most of the family now won tube-well. They also have mobile phones. The households in most cases use safer sources of water for drinking (tube well water 99.5\%) as well as for other purposes. Majority of the households $(61.2 \%)$ using hygienic latrine while $39 \%$ use unhygienic latrine (e.g. pit latrine without slab, flush to unsafe hole or hanging latrine and no latrine/bush/open field). The proportion of open or hanging latrine is lower in the study area compared to national estimate.

In addition, the section that follows we will explain every components of sustainable livelihood frameworks in order to see whether the lemon farmers have achieved sustainability in their livelihood.

Natural assets (access to lemon land): In the study area there was limited access to the natural assets like forest land, khas land, public water bodies etc. When the landless people got the access to the khas land by registering under the government Department, they are now entitled for the same. They are now using this khas property for their livelihood to make better income and increase employment opportunity

Physical assets (improved house built): Since they are engaged in the lemon production, their workforce giving them the opportunity of earning and thus helping them to meet their basic needs. Most of the lemon growers are now self-employed and have improved housing accommodation, sanitation, better physical assets.

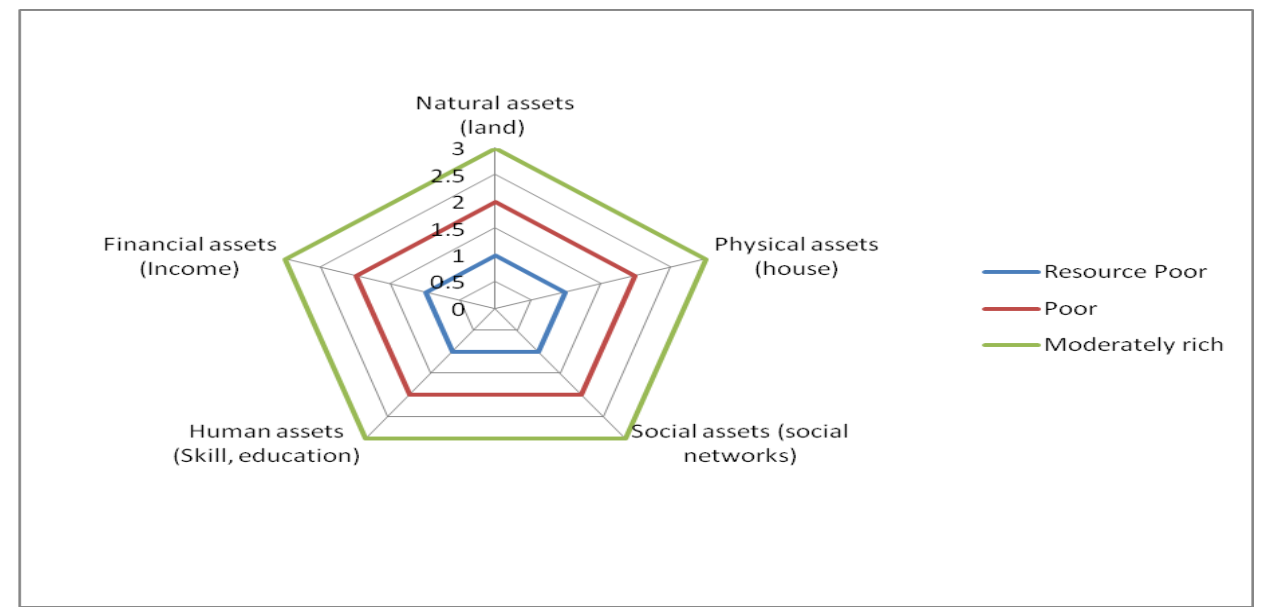

Figure 3: Livelihood assets of lemon producers in Kathalia

Social assets (social networks): The people of the Kathalia are now connected to multiple networks and stakeholder due to their involvement in lemon production. Lemon cultivation bridged a linkage with the lemon businessman, intermediary as well as the local market. Thus they are incorporated in the market and the supply chain. Yet, this social networks are still very limited and mostly within the local area.

Human assets (health services, education): With ten years of experience of lemon production in the field and by themselves, the lemon growers are now skilled enough. Their knowledge and awareness has also increased. They are now getting better education, healthcare and other livelihood facilities as well. 
Financial assets (capital/income, credit): Lemon production is a year round enterprises which required labor force throughout the year. Thus people of Kathalia are now getting regular earning from lemon production as well as by selling labor in the same enterprise. The financial assets of lemon producers have been increasing for the last 10 years.

\section{Women's participation in lemon production and empowerment}

In-depth interviews with the female farmer reveal economic empowerment women in Kathalia and their increased access to the market. In cultivation and production process, most of the women are involved as female labor. Thus, women of Kathalia got regular job (from $8 \mathrm{am}$ to $4 \mathrm{pm}$ ) in the lemon production field, and they earned Tk. 200.00 to 300.00 daily, which contributed in maintaining their family expenditure. Lemon cultivation also increased female participation in community. The information presented in the table below shows women' involvement in different lemon production practices.

Table 3: Types of lemon production activity and nature of participation by men and women

\begin{tabular}{|l|c|c|}
\hline Production activity & Men participation & Women participation \\
\hline Cutting/seedlings preparation & yes & Limited \\
\hline Land preparation & Yes & Yes \\
\hline Budding of lemon & Yes & No \\
\hline nursing of bud (watering) & Yes & Yes \\
\hline Transplanting of the lemon cuttings & Yes & Yes \\
\hline Fertilizers application & Yes & Yes \\
\hline Intercultural operations & Yes & No \\
\hline Irrigation & Yes & Yes \\
\hline Pest \& disease control & Yes & Yes \\
\hline Harvesting of lemon & Yes & No \\
\hline Sorting & Yes & No \\
\hline Packaging & Yes & Yes \\
\hline Sale in the market & \multicolumn{2}{c|}{} \\
\hline
\end{tabular}

During the field visits it was found that along with household members (male, female and children), hired labors (both male and female) were also involved in lemon production. Production activities were dominated by joint participation of male and female include seedling raising, gap filling, irrigation, plant protection and post harvest activities (Table 3). The involvement of female was higher in seed storage, seed drying, plant protection, gap filling, threshing, scooping, and irrigation, while male was more involved in seedling raising, land preparation, transplantation and weeding and mulching (Table 3). Children were also found to assist mostly in irrigation, gap filling, threshing and seed drying. Male hired labors were mostly engaged in seedling raising, land preparation, manures and fertilizer application, transplantation and weeding and mulching. Women worked as hired labors mainly for roughing and scooping.

In the study area it was observed that the women along with their husband decided some household decisions like purchasing food, buying cloth and family planning. In case of child education, health and sanitation and daily household expenditure, women had high decision making power in their house. Husband share the lemon selling money among their female members of the family. They take decision jointly with their female members of the family for arranging marriage ceremony of their family members. 


\section{Harvard Analytical Framework: Women empowerment in Kathalia}

The Harvard Analytical Framework is described as a "gender analysis framework" (Rao et al., 1991; Williams et al., 1994), and tend to focus on who has access to and control of different resources (Overholt et al., 1985.) Based on the Harvard Analytical Framework on Women Empowerment, this study shows that women in Kathalia gained high access to different livelihood assets such as housing, household utensils, crops and vegetables, ornaments, poultry, education, saving etc. However, they have high control over only very few assets such as ornaments which traditionally belong to women. Although women have medium access to income, they don't have control over it. With regards to land, women have low access and no control over it. Although women have high access to saving, they lack the control over it. The following table shows a detail list of livelihood assets and state of access and control over by the women in Kathalia.

Table 4: Harvard Framework on Women empowerment in Kathalia

\begin{tabular}{|l|l|l|l|l||}
\hline \multirow{2}{*}{ Content } & \multicolumn{2}{l}{ Access to } & \multicolumn{2}{l|}{ Control over } \\
\cline { 2 - 5 } & Homen & Men & Women & Men \\
\hline \multirow{2}{*}{ Land } & Low & High & No & High \\
\hline House/building & High & High & No & High \\
\hline Household utensils & High & No & High & Low \\
\hline Crops and vegetables & High & High & No & High \\
\hline Poultry (bird) & & & & \\
\hline Homestead & High & High & No & High \\
\hline Labor & High & No & Low & Medium \\
\hline Education & Medium & Medium & No & High \\
\hline Different skill based training & Medium & High & Medium & High \\
\hline Awareness session & High & High & Medium & High \\
\hline Income & Medium & High & Medium & High \\
\hline Profit & High & Medium & High & High \\
\hline Expenditure power & Medium & High & Low & High \\
\hline Treatment & Low & High & No & High \\
\hline Savings & Low & High & No & High \\
\hline Political power & High & High & Medium & High \\
\hline \hline
\end{tabular}

\section{Problems and possible solutions}

There are acute infestation of some pests and diseases in lemon cultivation. Lemon butterfly (Papilio demoleus L), green caterpillar, leaf miner (Phyllocnistis citrella St), die back (Colletotrichum gloeosporioide), leaf scald, canker (Xanthomonas axonopodis), greening (Candidatus liberibacter asiaticus) create a high production loss. Farmers use different types of pesticides and insecticides for reducing their yield loss. 
The total irrigated area of the village is 60 percent of cultivable land and the remaining 40 percent is rain fed. Irrigation problem in the dry season is a common problem of the study area. Long time draught reduces the lemon production which has impact on the cost of production. Yield loss reduces the profit margin of the lemon farmers. In order to reduce the yield loss, they took some group initiatives, such as establish Deep Tube Well (DTW) and Shallow Tube Wells (STW) irrigation pump near their lemon garden. There are seven STWs and one DTW in the study area. There are no storage facility and processing plant for lemon in Kathalia. In the peak season while there is high production of lemon, the producers get low prices compared to the off-season. The lemon producers get minimum technical support from the pesticide dealers. They lack proper technical guidance and support from DAE as well as from other development partners in that area. Hence, the lemon cultivators are suffering from low production instead of potential yield of lemon. Local middlemen are now controlling the lemon business throughout the year and the producers have to sale their lemon as per the prices set by the middleman. Moreover, the lemon cultivator cannot bargain for higher prices as there is no other market opportunity in Kathalia.

Farmers took micro credit from different NGOs like BRAC, ASA, BURO Bangladesh, Gameen Bank, ASPADA and local Rupali Samabai Samity to support their small business, crop production, cow-goat-poultry rearing etc. Almost $80 \%$ villagers got loans from NGOs before starting the vegetable and crop production. Though lemon cultivation stated 10-12 years ago, still there is no cooperative for lemon growers. Even, the lemon producers did not able to form a common interest Group so that they will fight for their interest and to promote a financial institutional development.

\section{Conclusion}

Livelihood of Kathalia community exclusively depends on lemon cultivation. All other economic activities revolve around lemon production practices. Before citrus cultivation, the socio-economic situation of Kathalia community was very poor. After introduction of lemon cultivation in the area in 2000, the socio-economic situation of the area has changed gradually. They earn more money from the lemon cultivation and spend more for their family need. Women became empowered over the decade. Female members of the family now contribute to in decision making process. Rural poor women including land less women, women headed family member, widow are now added to the productive forces. They work in the lemon field and earn 200-400 Taka daily. It has increased women participation in different socio-cultural programs. Lemon cultivation has created other employment opportunities for the local people like power tiller driver, irrigation pump driver, fertilizer \& pesticide retailer, small lemon collector, lemon supplier etc. All these contribute to the overall economy the study area. Yet, there are some limitations also. Lack of cooperative society, financial support, credit facility, technical support, storage facility and marketing support create problems for achieving sustainability in lemon production. 


\section{References}

[1] Ahmad, I., Mehmood, Z.,Mohammad, F., (1998). 'Screening of some Indian medicinal plants for their antimicrobial properties', Journal of Ethnopharmacology 62:183-193.

[2] BBS (2015). Statistical Pocket Bangladesh (2014). Dhaka: Ministry of Planning.

[3] FAO (2003a). Citrus Fruit. Medium-term prospects for agricultural commodities Projections to the Year 2010. Series title: FAO Commodities and Trade Technical Papers-1, Food Agriculture Organization of the United Nations, Rome.

[4] FAO (2003b). Selected indicators of food and agriculture development in Asia-Pacific region1999-2002. Food and Agriculture Organization of the United Nations, Rome.

[5] Hels, O., Kidmose, U., Larsen, T., Hassan, N., Tetens, I.,Thilsted, S. H. (2003). 'Estimated nutrient intakes and adequacies in Bangladesh change when newer values for vitamin A, iron and calcium in commonly consumed foods are applied', International Journal of Food Sciences and Nutrition 54(6): 457-465.

[6] Khan, M. R.,Ahmed, F. (2005). Physical status, nutrient intake and dietary pattern of adolescent female factory workers in urban Bangladesh. Asia Pacific Journal of Clinical Nutrition 14(1):19-26.

[7] M.S. Kabir, Hou, X, Akther, R, Wang, J, Wang, L. (2012). 'Impact of Small Entrepreneurship on Sustainable Livelihood Assets of Rural Poor Women in Bangladesh', International Journal of Economics and Finance 4(3):265-280.

[8] Nielsen, H. (2000). Food and nutrient intake among females in rural Bangladesh. Master in Human Nutrition Dissertation, Research Department of Human Nutrition, The Royal Veterinary and Agricultural University, Copenhagen, Denmark.

[9] Overholt, C., Anderson, M., Cloud, K.,Austin, J. (1985). 'Women in Development: A Framework for Project Analysis', In C. Overholt, M. Anderson, K. Cloud, and J. Austin (eds.), Gender Roles in Development Projects: A Case Book. West Hartford, Conn.: Kumarian Press.

[10] Rao, A., Anderson, M. B., Overholt, C. A. Gender Analysis in Development Planning: A Case Book. West Hartford, Conn.: Kumarian Press, 1991.

[11] Rao, A., Anderson, M. B., and Overholt, C. A. (1991) Gender Analysis in Development Planning: A Case Book. West Hartford, Conn.: Kumarian Press.

[12] Salehin, M., Kabir, M, Morshed, K., Farid, K. (2009). 'Socioeconomic changes of farmers due to adoption of rice production technologies in selected areas of Sherpur district' Journal of Bangladesh Agricultural University 7(2): 335-341.

[13] Spreen, T. H. (2001). Projections of World Production and Consumption of Citrus to 2010. Proc. China FAO Citrus Symposium, 14-17 May 2001. Beijing.

[14] Williams, S., Seed, J.,Mwau, A. (1994). Oxfam Gender Training Manual. Oxford: Oxfam.

\section{Article history:}

- $\quad$ Received 25 March 2016

- Accepted 15 May 2016 